\title{
Acute intracranial subdural hematoma following incidentally durotomy after revisional lumbar spinal surgery; case report
}

\author{
Sung Hwa Paeng ${ }^{1 *}$ and Sae Hoon $\mathrm{Im}^{2}$ \\ *Correspondence: shpaeng@empas.com

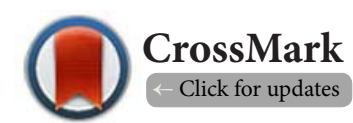 \\ 'Department of Neurosurgery Medicine, School of Medicine, Inje university Busan paik hospital, Bok Ji Ro 75, Busanjin-Ku, Busan, \\ South Korea. \\ ${ }^{2}$ Department of Anesthesiology Medicine, School of Medicine, Inje university Busan paik hospital, Bok Ji Ro 75, Busanjin-Ku, Busan, \\ South Korea.
}

\begin{abstract}
A fifty-four-year-old man was admitted with left leg severe radiating pain with a history of previous lumbar spinal fusion(L5/S1) presented with upper adjacent level spinal stenosis. He underwent a revision spinal arthrodesis from L4 to L5. Dissection at adhesion lesion in L4/5 level resulted in a unintended 3- $\mathrm{mm}$ dural tear with CSF loss. The durotomy was primarily repaired during the surgery. Total perioperative blood loss was $1900 \mathrm{~mL}$ and fliud replacement was about $4000 \mathrm{~mL}$. On the fourth postoperative day, the patient had slightly headache. He was treated conservatively (Hydration and NSAIDs). On the tenth day, the patient complained of severe headache with the nousea, vomiting. A brain CT was obtained and revealed acute subdural hematoma in left frontoparietal area. We did not have surgery because of no intracerebral mass effect, but follow up brain CT. The hematoma was not increased and resolved. The patient made an uneventful recovery. This case reminds that subdural hematoma can complicate durotomy during spine surgery. Therefore, neurological deterioraion in the postoperative period rule out the diagnosis, especially in complicated by dural tears on revisional spinal operation.
\end{abstract}

Keywords: Acute subdural hematoma, headache, spinal stenosis, spinal arthrodesis

\section{Introduction}

Cerebrospinal fluid (CSF) leakage induced headache is often after spinal acupcuture and unintended durotomy and results from on pain sensitive structures within the cranium [1-3]. Moreover, It may tear the intracranial subdural veins and form intracranial subdural hematoma, as a result of traction on cerebral veins after unintended dural tear.

We report a case of intracranial subdural hematoma occurring after a spinal dural tear that was made unintentionally during the course of a posterior laminectomy and facetectomy in adjacent spinal lesion (L4/5 level). The possible pathophysiological mechanisms are discussed.

\section{Case report}

A fifty-four-year-old man was admitted with lower back pain and right leg severe radiating pain with a history of previous lumbar spinal fusion(L5/S1) presented with upper adjacent level spinal stenosis. The MRI and CT was shown in Figures $1 \mathrm{~A}$ and 1B. We planned a revision spinal arthrodesis from $L 4$ to $L 5$, Hypertension and diabetes mellitus had been noted for years and were under regular medical treatment. All laboratory data including coagulation status were within normal limits on admission. Preoperative blood pressure was $150 / 80 \mathrm{mmHg}$ with heart rate around 85 beats min. Anesthesia was induced with thiopentone and fentanyl. Tracheal intubation was facilitated by succinylcholine. Anesthesia was maintained with isoflurane $4-5 \%$ in $\mathrm{O}_{2}(300 \mathrm{~mL} / \mathrm{min})$. The arterial hemoglobin $\mathrm{O}_{2}$ saturation remained between $96-100 \%$ during surgery. The patient was ventilated mechanically and end-tidal $\mathrm{CO}_{2}$ maintained between $36-40 \mathrm{mmHg}$. The patient underwent posterior laminectomy for $L 4 / 5$ under the microspcopy and posterior spinal fusion. Dissection at adhesion lesion in $L 4 / 5$ level resulted in a unintended 3-mm dural tear with CSF loss. The durotomy was primarily repaired with 6-0 prolene watertightly. We reinforced with Tachacomb and fibrin selant(TISSEEL).

A subfascial hemovac drainage system was placed and set to positive pressure. The wound closed layer by layer watertightly. Total Perioperative blood loss was $1900 \mathrm{~mL}$ and total intravascular replacement included two unit packed blood cell and about $4000 \mathrm{~mL}$ of crystalloids during the surgery. There was continuous CSF-like drainage from the hemovac utill seven days postoperatively. Fortunately, the patient did not have leaking fluid from lumbar incision and the patient did not have wound problem after removal of hemovac, which MRI was shown in Figure 2A. On the physical examination, the patient was no neurologic problem. On the fourth postoperative day, the patient complained of a persistent, throbbing left retroorbital headache. He was hydrated with fluids and treated with NSAIDs. The symptoms improved but did not appear. On the tenth day, the patient complained of severe headache with the vomiting. Moreover, general weakness 
Paeng et al. Journal of Anesthesiology \& Clinical Science 2014,

and loss of appetite were noted. He became drowsy. A brain $\mathrm{CT}$ and MRI was obtained and revealed subdural hematoma in left frontoparietal area. It was shown in Figures 2B and 2C. We did not operation because of no intracerebral mass effect and follow up brain CT. The hematoma was not increased and resolved. The patient made an uneventful recovery without any neurological sequale.
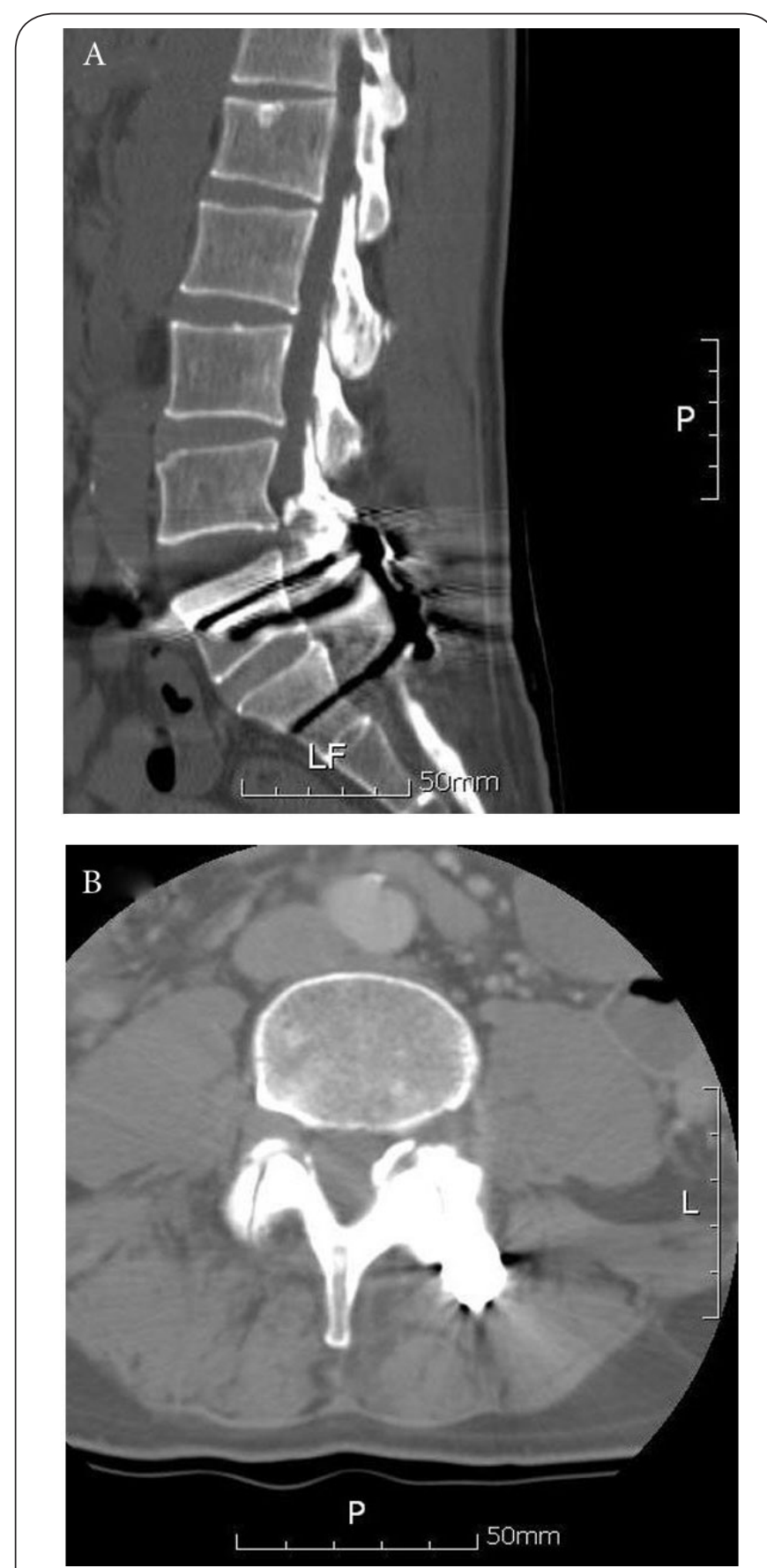

Figure 1. Preoperative sagittal. (A) and axial (B) lumbar CT showing Previous posterior fusion L5/S1 and foraminal stenosis and calcified hypertrophic ligamentum \& facet lesion on left lumbar $4 / 5$ level.
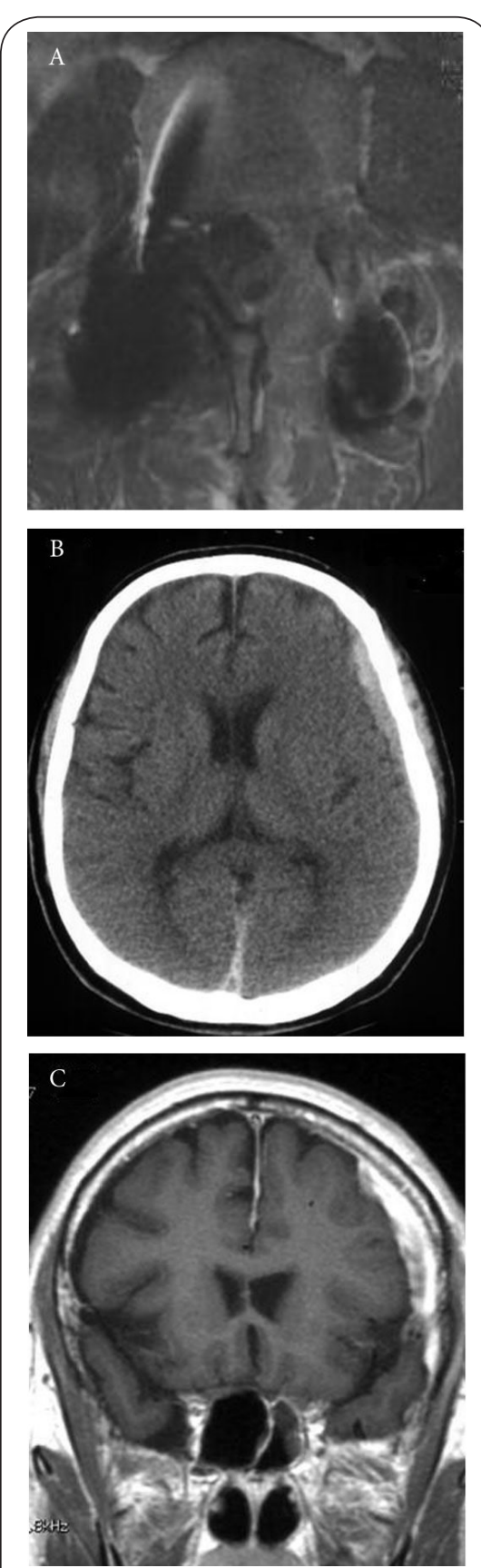

Figure 2. Postoperative axial (A) lumbar MRI reveling the well decompressed foramen but fluid collection in laminectomy site Brain axial (B) CT scan showing the intracranial subdural hematoma and coronal (C) brain MRI

showing the acute stage on left frontotemproparietal lesion and no midline shifting.

\section{Discussion}

Dural tear is well-known complications of spine surgery, with a prevalence of 1 to $17 \%$ [4-7]. From $0.67 \%$ to $10 \%$ in primary 
lumbar degenerative surgery [3], and from $13.2 \%$ to $21 \%$ in revision lumbar surgery [8]. The causes of dural tear during primary operation include eroded or thin dura, dura adhesion, and redundant dura in severe spinal stenosis patients.

It is particularly prevalent in patients who have epidural fibrosis and scar tissue adherent to the dura during revision of spine surgery [3]. In general, revision surgeries have a greater chance of dural tears than primary surgeries because of adhesions and scarring around the dura. If dura tear deveope on spinal surgery, primary repair is still considered the gold standard. Various methods for treating identifiable durotomies exist, including primary repair, fat/muscle graft, collagen matrix onlay, and fibrin glue [9]. Moerover, The operative technique plays a key role in avoiding injury to the dural tissue.

Subdural hematoma on brain has been reported after dural tear with persistent leakage of CSF [10]. However, pathophysiological mechanism is unclear. One hypothesis is that CSF leakage reduces intraspinal as well as intracranial pressure. The CSF dynamics may result in a caudally-directed movement of the spinal cord and brain, which in turn stretches the painsensitive structures, dura, cranial nerves and bridging veins $[10,11]$. Cerebral veins drain into dural sinuses that are adherent to the inner table of the skull. Bridging veins are more fragile in the subdural portion than in the subarachnoid space [12]. Therefore, mechanical stress exerted on the bridging veins will rupture at their weakest point in the subdural space. It is presumed that CSF leaked via a dural fistula created by accidental durotomy may cause a downward brain displacement, which in turn stretches and tears the bridging veins, and results in a intracranial subdural hematoma. The symptoms of such intracranial hematoma are persistent headache, sometimes accompanied with other symptoms and signs such as vomiting, somnolence, confusion and neurologic mental change. Brain CT will confirm the diagnosis and must be performed as quickly as it is suspected.

Another hypothsis is that dehydration may increase the risk of imbalance between CSF leakage and production [13]. Dehydration induced reduction of brain volume could lead to subdural hemorrhage. Low intracranial pressure, as a result of perioperative dehydration, promotes excessive blood congestion in the bridging veins with consequent dilatation and increasing tension of the vessels, which are further pulled by a caudal displacement of the brain, and consequently more vulnerable to the movement of the brain within its coverings due to the decreased cerebral volume [10]. In our case, total intraoperative blood loss was $1900 \mathrm{~mL}$, fluid replacement totally was $4000 \mathrm{~mL}$. Therefore, we could rule out dehydration. Minor head injury may also cause to a subdural hematoma in elderly patients and spontaneous hematoma is also observed in anticoagulopathy patients. In our case, the patient did not have a history of head injury in preoperative period and he did not take anticoagulants and the postoperative coagulation status was within normal limits. During the postoperative hospital care, the patient did not injury of head trauma. Ifdura tear is detected during surgery, then they can be closed intraoperatively, after which the patients are treated with specialized postoperative care, such as bed rest and vigilance for positional headaches. However, if a dural tear is noted postoperatively, it may or may not be associated with persistent signs and symptoms. Many can result in asymptomatic pseudomeningoceles that can be observed or followed clinically. However, if signs or symptoms after surgery persist, then additional postoperative treatment and evaluation may be needed.

\section{Conclusions}

We reminds that subdural hematoma can complicate durotomy during spine surgery. Therefore, neurological deterioration in the postoperative period rule out the diagnosis, especially in complicated patients by dural tears on revisional spinal operations. Therefore, because intracranial hemorrhage can present with variable symptoms, it is important that surgeons recognize and aggressively evaluate early signs of neurologic deterioration to prevent a potentially life-threatening complication.

\section{Competing interests}

The authors declare that they have no competing interests.

\section{Authors' contributions}

\begin{tabular}{|l|c|c|}
\hline Authors' contributions & SP & SI \\
\hline Research concept and design & $\checkmark$ & $\checkmark$ \\
\hline Collection and/or assembly of data & $\checkmark$ & -- \\
\hline Data analysis and interpretation & $\checkmark$ & $\checkmark$ \\
\hline Writing the article & $\checkmark$ & -- \\
\hline Critical revision of the article & $\checkmark$ & -- \\
\hline Final approval of article & $\checkmark$ & $\checkmark$ \\
\hline Statistical analysis & $\checkmark$ & -- \\
\hline
\end{tabular}

\section{Acknowledgement}

I would like to thank Mina Bae for her support in preparing the manuscript.

\section{Publication history}

Editor: Federico Bilotta, University of Rome "La Sapienza", Italy. EIC: D. John Doyle, Case Western Reserve University, USA. Received: 26-Feb-2014 Final Revised: 22-Mar-2014 Accepted: 17-Apr-2014 Published: 26-Apr-2014

\section{References}

1. Baldwin LN and Galizia EJ. Bilateral subdural haematomas: a rare diagnostic dilemma following spinal anaesthesia. Anaesth Intensive Care. 1993; 21:120-1. | PubMed

2. Bjarnhall $M$, Ekseth $K$, Bostrom $S$ and Vegfors $M$. Intracranial subdural haematoma--a rare complication following spinal anaesthesia. Acta Anaesthesiol Scand. 1996; 40:1249-51. | Article | PubMed

3. Wang JC, Bohlman HH and Riew KD. Dural tears secondary to operations on the lumbar spine. Management and results after a two-yearminimum follow-up of eighty-eight patients. J Bone Joint Surg Am. 1998; 80:1728-32. | Article | PubMed

4. Eismont FJ, Wiesel SW and Rothman RH. Treatment of dural tears associated with spinal surgery. J Bone Joint Surg Am. 1981; 63:1132-6. I 
Article | PubMed

5. Finnegan WJ, Fenlin JM, Marvel JP, Nardini RJ and Rothman RH. Results of surgical intervention in the symptomatic multiply-operated back patient. Analysis of sixty-seven cases followed for three to seven years. J Bone Joint Surg Am. 1979; 61:1077-82. | Article I PubMed

6. Jones AA, Stambough JL, Balderston RA, Rothman RH and Booth RE, Jr. Long-term results of lumbar spine surgery complicated by unintended incidental durotomy. Spine (Phila Pa 1976). 1989; 14:443-6. | Article | PubMed

7. Kitchel SH, Eismont FJ and Green BA. Closed subarachnoid drainage for management of cerebrospinal fluid leakage after an operation on the spine. J Bone Joint Surg Am. 1989; 71:984-7. | Article | PubMed

8. Sin AH, Caldito $G$, Smith D, Rashidi M, Willis B and Nanda A. Predictive factors for dural tear and cerebrospinal fluid leakage in patients undergoing lumbar surgery. J Neurosurg Spine. 2006; 5:224-7. | Article I PubMed

9. Narotam PK, Jose S, Nathoo N, Taylon C and Vora Y. Collagen matrix (DuraGen) in dural repair: analysis of a new modified technique. Spine (Phila Pa 1976). 2004; 29:2861-7; discussion 2868-9. | Article | PubMed

10. Lu CH, Ho ST, Kong SS, Cherng CH and Wong CS. Intracranial subdural hematoma after unintended durotomy during spine surgery. Can $\mathrm{J}$ Anaesth. 2002; 49:100-2. | Article | PubMed

11. Dickerman RD and Morgan J. Acute intracranial subdural hematoma following a lumbar CSF leak caused by spine surgery. Spine (Phila Pa 1976). 2006; 31:1513-4. | Article I PubMed

12. Yamashima $T$ and Friede RL. Why do bridging veins rupture into the virtual subdural space? J Neurol Neurosurg Psychiatry. 1984; 47:121-7. | Article | PubMed Abstract | PubMed Full Text

13. Chodobski A, Szmydynger-Chodobska J and McKinley MJ. Cerebrospinal fluid formation and absorption in dehydrated sheep. Am J Physiol. 1998; 275:F235-8. | Article | PubMed

\section{Citation:}

Paeng SH and Im SH. Acute intracranial subdural hematoma following incidentally durotomy after revisional lumbar spinal surgery; case report. $J$ Anesthesiol Clin Sci. 2014; 3:3.

http://dx.doi.org/10.7243/2049-9752-3-3 